\title{
Tropical Mangrove Mapping Using Fully-Polarimetric Radar Data
}

\author{
Bambang H. Trisasongko
}

Department of Soil Science and Land Resources, Bogor Agricultural University. Jalan Meranti, Dramaga. Bogor 16680. Indonesia. Email: trisasongko@gmail.com

\begin{abstract}
Although mangrove is one of important ecosystems in the world, it has been abused and exploited by human for various purposes. Monitoring mangrove is therefore required to maintain a balance between economy and conservation and provides up-to-date information for rehabilitation. Optical remote sensing data have delivered such information, however ever-changing atmospheric disturbance may significantly decrease thematic content. In this research, Synthetic Aperture Radar (SAR) fully polarimetric data were evaluated to present an alternative for mangrove mapping. Assessment using three statistical trees was performed on both tonal and textural data. It was noticeable that textural data delivered fairly good improvement which reduced the error rate to around 5-6\% at L-band. This suggests that insertion of textural data is more important than any information derived from decomposition algorithm.
\end{abstract}

Keywords: mangrove; Mimika; polarimetric decomposition; SAR polarimetry; textural occurrence measures.

\section{$1 \quad$ Introduction}

Geographically, mangroves are distributed in the tropical region and dominate coastline areas. Depending on the extent of warm water from the tropics, mangrove forests are also found in subtropical zones such as southern Australia and New Zealand. Generally, mangroves grow in tropical climates in either saline or freshwater environments. Tidal waves are generally responsible for nutrient supplies and indirectly minimize competition from other vegetation. The tide also plays an important role in transporting the seedlings; hence promotes the vast distribution of mangrove species.

In an undisturbed environment, mangroves can grow fast and become densely populated. Therefore, they provide ideal natural protection for the coastal region from erosion. Since the December 2004 tsunami hit north Indian Ocean and delivered wide impacts on socio-economic aspects of Indonesia, Thailand and Sri Lanka, awareness of the importance of coastal protection has been raised. While alternative schemes can be implemented to minimize the impacts of disasters, mangrove forest has a proven record of coastal protection against cyclone and tsunami [1]. Due to its uniqueness and biodiversity richness,

Received May $27^{\text {th }}, 2009$, Revised August $8^{\text {th }}, 2009$, Accepted for publication August $10^{\text {th }}, 2009$. 
mangrove has been evaluated as an indicator of changes in coastal environment [2]. There have been very strong development pressures on mangrove habitat. Aquacultures are probably the most dominant factor responsible for the degradation. In the last two decades, a large number of mangrove conversions have been indicated since the coastal zone is a prime land for shrimp farming. Large areas of mangrove forest have been depleted, particularly in Asia [3].

As with other forested sites, assessments on the biophysical properties of mangrove have been conducted. For this purpose, remotely sensed data have been widely exploited, for instance Diaz and Blackburn [4] on the estimation of leaf area index or Mougin et al. [5] on the assessment of biomass. However, basic information such as maps of mangrove species distribution are often not available. Obviously, maps are important to assist with further analysis of coastal vulnerability and to guide field assessments.

Using various multispectral and SAR images, Aschbacher et al.[6] attempted to map a mangrove forest in Thailand using a density-based mangrove classification scheme. Data analysis based solely on SPOT imagery was found inadequate to separate different densities of mangrove, mostly due to its limited spatial resolution. A better result was obtained when a SPOT and ERS-1 SAR data were combined.

SAR polarimetry data have been used extensively for mapping vegetation in the tropics. One of the earliest applications was reported by Pasqualini et al.[7] using Shuttle Imaging Radar SIR-C. Based on the amplitude data, reliable accuracy was not achieved on a per-pixel classification scheme while incorporating textural information improved mangrove separation based on its density. A mixture of different polarizations and wavelengths such as ERS and JERS combined was found useful to improve land cover mapping of a coastal region [8], especially for discriminating high and low-density mangrove from their natural surroundings.

Held et al. [9] attempted to map mangrove species by means of radar polarimetry data. Several mangrove genera were successfully identified, including Rhizophora, Bruguiera and Ceriops. All possible frequencies (C-, Land P-band) of the AIRSAR system were explored, in addition to a L-band pedestal image. Nevertheless, low accuracy was attained using the AIRSAR only dataset. An appreciable accuracy was achieved only after combining CASI and AIRSAR data. The research was solely based on the amplitude data, which offers a simple representation of complex radar data that can be assessed by common image processing techniques. 
Previous reports primarily focused on the use of tonal information (mainly backscattering coefficients) to characterize mangrove forest and limited papers have been presented to exploit textural information contained in polarimetric SAR data. The combination of tonal and textural information is considerably more important because of the availability of high spatial resolution radar data recently or nearly available (Table 1). Hence, the aim of this paper is to evaluate a combination of multi-parameter and texture information for retrieving mangrove distribution. In this research, decision tree analyses were employed to obtain a thematic map.

Table 1 Currently available spaceborne polarimetric SAR data.

\begin{tabular}{ccc}
\hline Sensors & Frequency & Polarimetric Modes \\
\hline ASAR & C-band & Single, Dual \\
PALSAR & L-band & Single, Dual, Full \\
TerraSAR & X-band & Single, Dual \\
Radarsat-2 & C-band & Single, Dual, Full \\
\hline
\end{tabular}

\section{$2 \quad$ Methodology}

\subsection{Study Site}

During the 2000 PACRIM-II airborne campaign, AirSAR system onboard NASA DC-8 acquired various test sites in the Pacific region including a mangrove forest on Mimika, Indonesia. Figure 1(a) presents location of the test site. The forest is situated adjacent to a large-scale mining waste disposal site; therefore monitoring the change is important to ensure minimal impacts on local community and the Lorentz National Park on the eastern border of mine concession. Various mangrove communities were found in the site, including Bruguiera gymnorrhiza, Avicennia alba and Sonneratia alba. Bruguiera species was dominant in this region, with scattered patches of mixed Avicennia and Sonneratia at the upper stream of the tributaries where fresh water was available. Using L-band horizontal polarisation radar data, mangrove forest can be discriminated from other land covers such as lowland forest and urban or bare surfaces. Montane forest on northern part of Figure 1(b) is slightly discernible which appeared darker than lowland forest. 


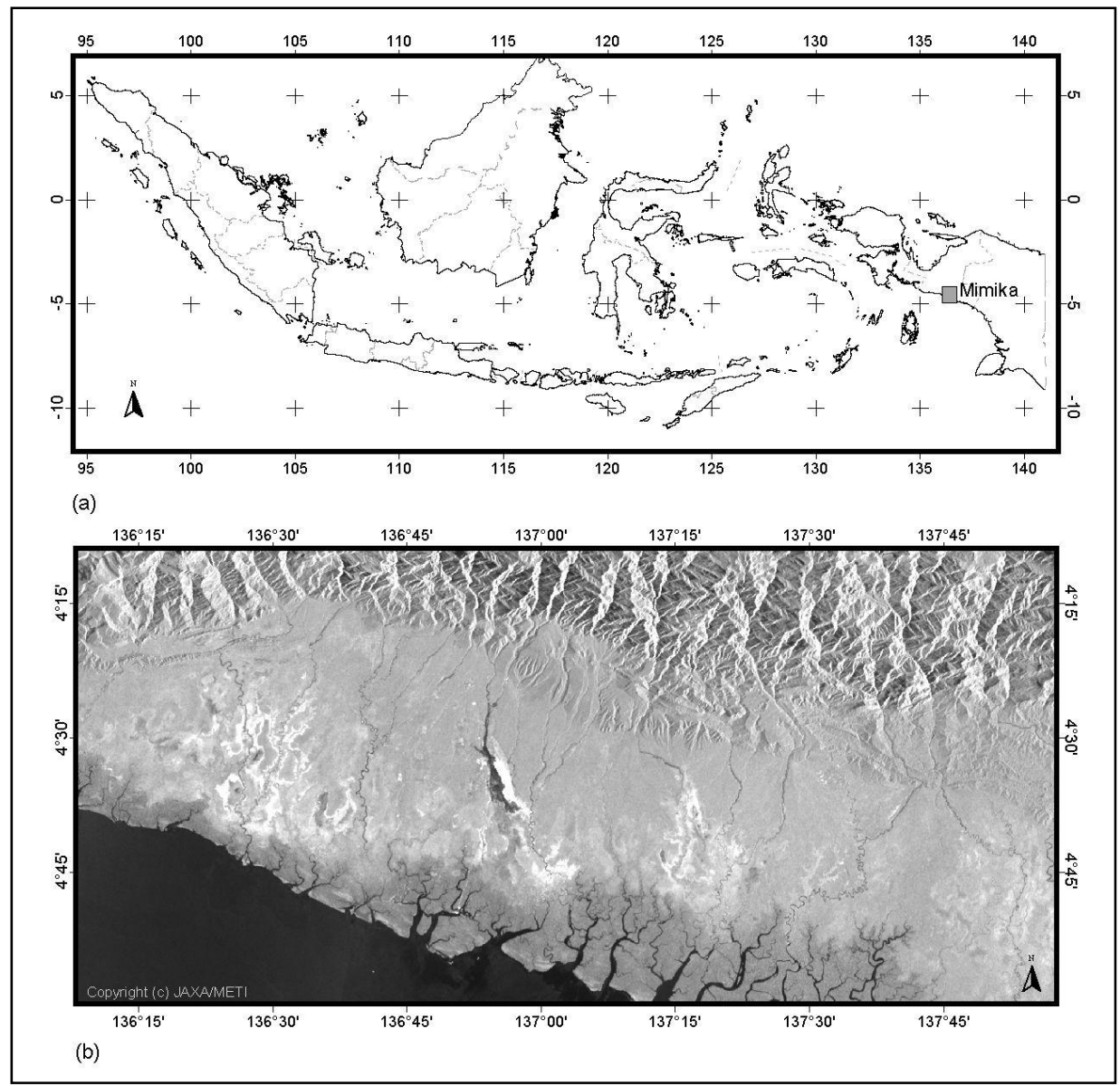

Figure 1 Test site Mimika (a) and a JERS-1 SAR scene showing abundant mangrove of south Papua coast (b).

\subsection{Data Analysis}

The main data for this chapter were AirSAR L- and P-band fully polarimetric images, originally stored in a compressed Stokes matrix. To be able to process the data, they were converted into a coherence $(T)$ matrix using Polsarpro software. The coherence matrix represents all information contained in the fully polarimetric data, including backscattering information and phase, defined as

$$
[T]=\left[\begin{array}{lll}
T_{11} & T_{12} & T_{13} \\
& T_{22} & T_{23} \\
& & T_{33}
\end{array}\right]
$$


To minimise speckle effects while maintaining clarity of the image, a $3 \times 3$ Lee filter was applied.

Decomposition by means of the Entropy-Alpha Angle algorithm [10] was implemented using $3 \times 3$ ensemble averaging. Two primary feature sets were obtained from the decomposition i.e. entropy and alpha angle. In this paper, additional features from eigen analysis were retrieved as suggested by Hellmann [11]. Hence the polarimetric feature vector consisted of 5 components:

$$
\vec{f}=\left[\begin{array}{c}
\bar{\alpha} \\
H A \\
H(1-A) \\
(1-H) A \\
(1-H)(1-A)
\end{array}\right]
$$

where $\alpha, H, A$ respectively denote alpha angle, entropy and anisotropy.

AirSAR imagery has a spatial resolution of 3.3 and $4.6 \mathrm{~m}$ in range and azimuth directions, which is considered high spatial resolution. As a result, texture information is revealed. To account for this information, occurrence texture measures (range, mean and variance) were applied on the Lambda image to represent backscattering information. The image was previously exploited as an additional input to recognize specific land cover classes [11]. A 9x9 window size was used for texture computation. Textural data were then integrated into a single dataset along with tonal information. In order to obtain a thematic map, the research employed supervised classification on the original coherence matrix $[T]$ or its combination with polarimetric decomposition and textural properties.

Sample data were taken based on field survey observations, classified aerial photograph and existing thematic mapping [12]. Pauli composites of L- and Pbands as well as sample location are presented in Figure 2. The data were then divided into two equal sized categories i.e. training and testing dataset. Training data were fed into three different decision tree algorithms namely Classification and Regression Trees (CART) proposed by Breiman et al.[13], C 4.5 [14] and Random Forests (RF) [15]. Assessment of accuracy was made by computing error rates (percentage of classification error in sampling location) on testing dataset. 


\section{$3 \quad$ Results and Discussion}

Error rates from combinations of polarimetric data representation and classification algorithms are presented in Table 2. In general, all decision tree algorithms were comparable in performance and produced fairly similar error rates. Except in an all-combined dataset, the CART algorithm delivered slightly better accuracy in a consistent way. It is, therefore, important to acknowledge that fairly old techniques may applicable for such analyses. From a broader perspective, this could be acceptable on an operational basis. Future research that compares different methods is still required to advocate better thematic maps and efficiency in data processing.

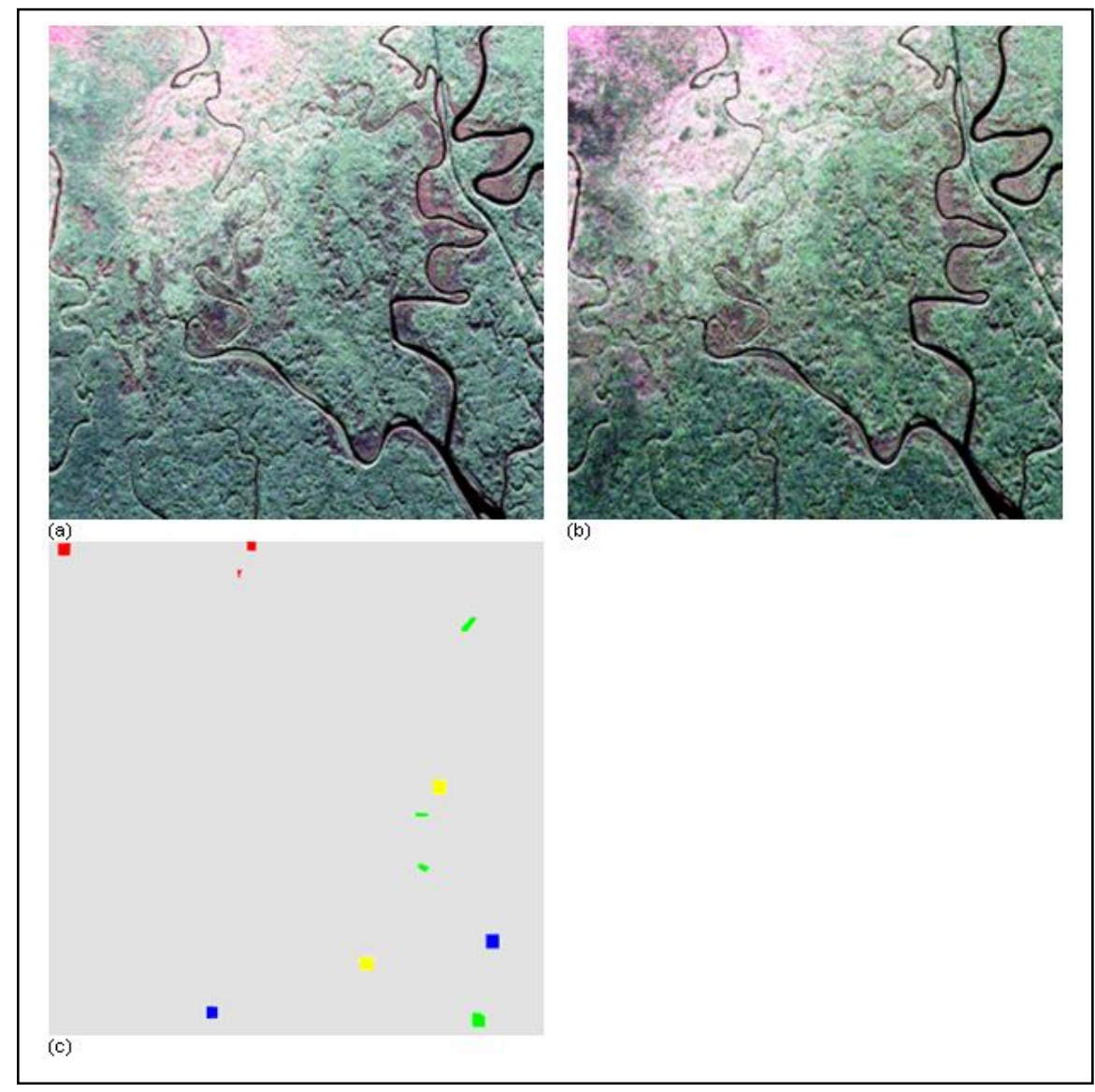

Figure 2 Color composite (Red: T22; Green: T33; Blue: T11) for L- (a) and Pband (b). Sampling data for supervised classification shown on (c). Color code: red:degraded mangrove; green:water; Bruguiera:blue; Sonneratia/Avicennia: yellow. 
Table 2 Error rates (per cent) based on testing dataset. T:original coherence matrix data; f:decomposition features; $x$ :textural data.

\begin{tabular}{cccccccc}
\hline & \multicolumn{3}{c}{ L-band } & & \multicolumn{3}{c}{ P-band } \\
\cline { 2 - 3 } \cline { 7 - 8 } Dataset & CART & C 4.5 & RF & & CART & C 4.5 & RF \\
\hline $\mathrm{T}$ & 15.87 & 16.91 & 17.07 & & 14.74 & 15.36 & 16.69 \\
$\mathrm{~T}+\mathrm{f}$ & 14.15 & 15.58 & 17.34 & & 12.25 & 13.66 & 13.56 \\
$\mathrm{~T}+\mathrm{x}$ & 5.80 & 6.24 & 6.79 & & 13.57 & 13.44 & 13.62 \\
$\mathrm{~T}+\mathrm{f}+\mathrm{x}$ & 6.77 & 5.90 & 6.77 & & 12.07 & 11.54 & 12.61 \\
\hline
\end{tabular}

Table 2 also indicates that additional information from polarimetric decomposition or texture contributes to the accuracy improvement, although by different degrees. Using tonal information only, P-band is preferable for delivering a better thematic map. This is due to the capability of its longer wavelength to penetrate thick canopy layers and allow the recording of information on ground-trunk interactions, which is important component in woody vegetation. The result is in agreement with previous assessments on tropical forests that P-band data are preferable to produce high accuracy maps [16].

\subsection{Contribution of Tonal Information}

Figure 3 presents a histogram of the main diagonal components of coherence matrix data. In general, degraded forest was distinguishable on all components. As shown, the coherence matrix provides good separation between water, vegetative covers and degraded forest. The $\mathrm{T}_{11}$ data contribute to the identification of odd-bounce (specular) scatterers such as water; hence good discrimination can be achieved on the separation of basic scattering mechanisms. The main challenge was differentiation between woody vegetation types. Primarily, cross-polarization data, or $\mathrm{T}_{33}$ in the case of the coherence matrix, could be beneficial for this problem. On both wavelengths, $\mathrm{T}_{33}$ data provide better information on land cover types, although separation is quite clear on the L-band data. This is probably due to excessive penetration of Pband data over mixed Sonneratia/Avicennia which is shorter than Bruguiera, therefore data captured by the sensor contained less information from trunks.

Additional information from polarimetric decomposition improved classification accuracy to some extent. Previously polarimetric decomposition parameters have been found useful when they are classified independently and without additional information. Hellmann [11], for example, found that just two Cloude-Pottier parameters (Entropy and Alpha angle) were able to classify four major land covers using simple feed forward neural networks. Borghys et al. 
[17] also mentioned success in using polarimetric features. That paper extended Hellmann's [11] research by incorporating not only an interferometric product but also adding spatial information. While additional interferometric SAR data can be useful to achieve better accuracy, the configuration requires multiple datasets through repeat-pass or tandem data acquisitions

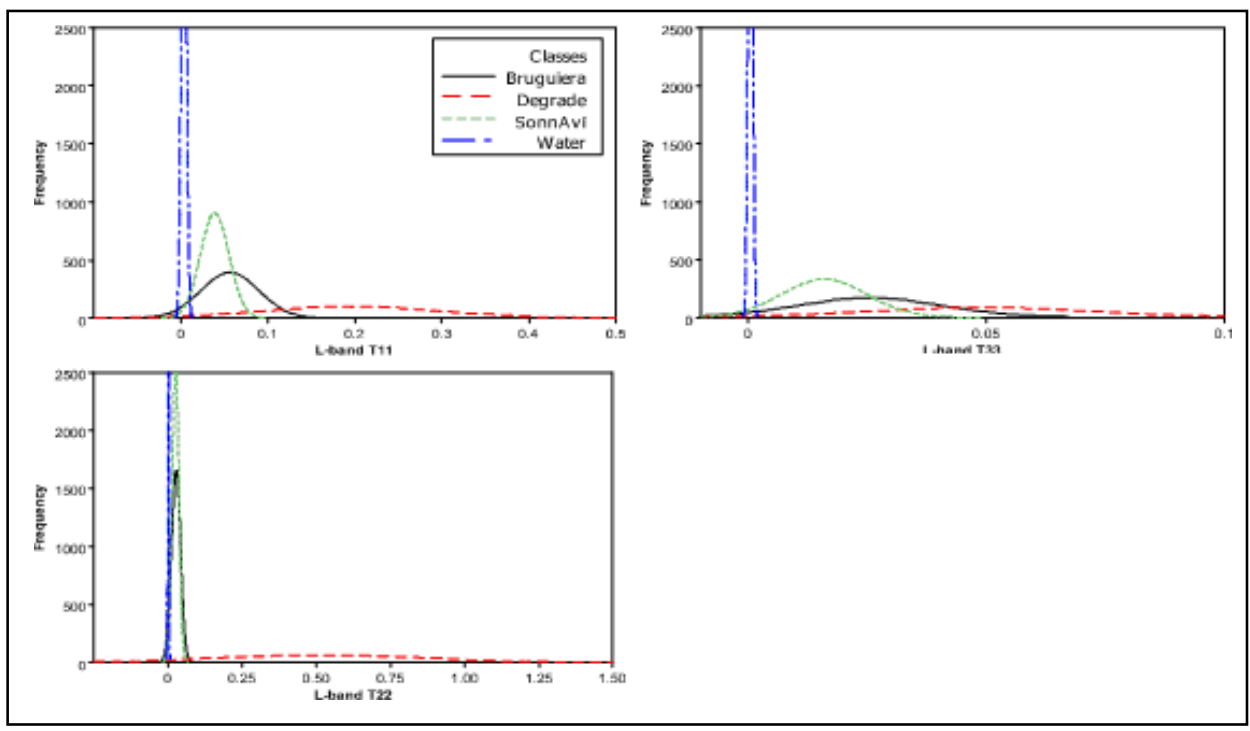

Figure 3 Histogram of main land covers at L-band.

Although decomposition parameters were found useful for various applications, it seems that such improvement in classification accuracy was not significantly achieved. Slightly better enhancement was observed on P-band data. Figure 4 presents a subset of the image showing only Bruguiera and Sonneratia/Avicennia communities. In general, all decomposition parameters provided little information on the discrimination. Only components of $\mathrm{H}(1-\mathrm{A})$ and $\mathrm{A}(1-\mathrm{H})$ delivered trivial enhancement which was reflected in decreasing error rates.

\subsection{Importance of Texture}

Table 2 presents additional information which demonstrates that incorporating texture data is another approach to improve classification accuracy. It is shown that inclusion of texture information with coherence matrix data seems more important than the use of a specific wavelength or addition of polarimetric features. Except in minor cases, texture processing supplied additional information particularly in separation between Bruguiera and 
Sonneratia/Avicennia. This indicates that even straightforward forms of texture analysis could convey a better map.

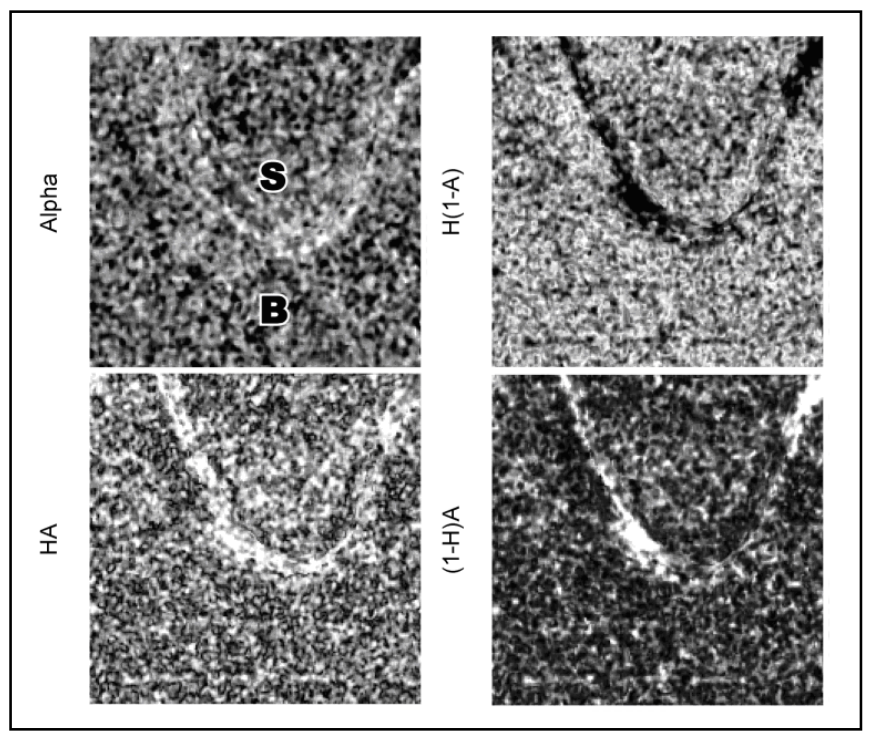

Figure 4 Cloude-Pottier polarimetric features of L-band.

Previously, van der Sanden and Hoekman [16] studied a textural component (grey level co-occurrence) and its application for land cover classification using polarimetric data. It was shown that texture significantly contributed to land cover discrimination where backscattering coefficient data had failed. This research confirms previous findings, and extends the comparison with recentlypopular decomposition methods.

Figure 5 shows a set of data derived from textural measures commonly available in remote sensing data analysis packages. Except for texture variance data, all textural properties contributed to discriminating woody vegetation types. L-band data show a greater role than of P-band, hence the improvement on classification accuracy was fairly significant.

\section{Conclusion}

Recently, fully polarimetric SAR data have become available at various wavelengths. While a range of reports have promoted P-band as the most suitable source of information, the sensor is not available on existing spaceborne platforms. Development of a platform has now been initiated by European Space Agency through the BIOMASS mission. At the moment, major forest applications rely on L-band data of Japanese ALOS PALSAR origin. 


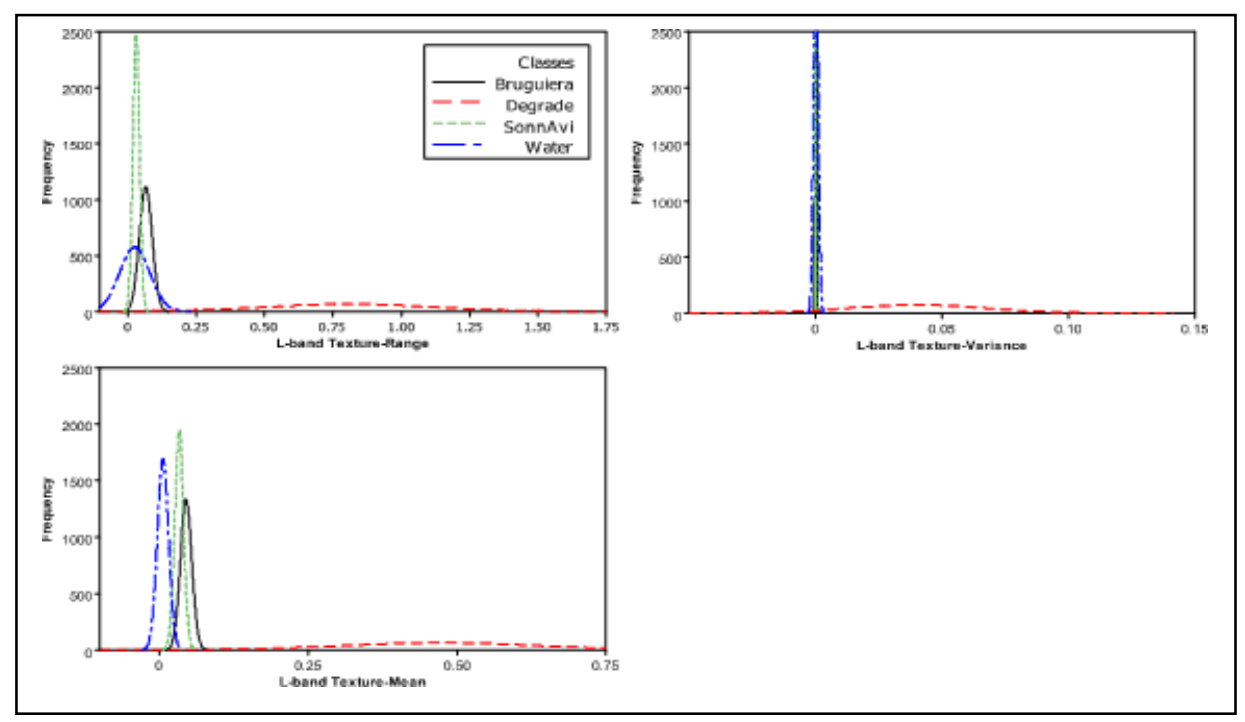

Figure 5 Contribution of texture information at L-band.

Using coherence data only, separation between major scattering objects (water, degraded forest and woody vegetation) was successful. However, discriminating different types of woody vegetation was a complicated task. Attempts to improve the discrimination using the decomposition features failed somewhat to distinguish Sonneratia/Avicennia communities from Bruguiera. In line with previous results, the use of P-band data is strongly recommended, although the error rates were fairly similar to L-band data.

Due to the nature of high-resolution imagery, textural information of the scene was shown to be more important than any tonal-based processing. Therefore, texture analysis shows considerable promise and the L-band data such as Japanese ALOS PALSAR are useful if texture analysis is considered.

This research indicates that the most preferable data type was a combination of polarimetric decomposition and textural information. Toolkits have been available on freeware basis which promote the widest use of fully polarimetric SAR for both research and implementation.

\section{$5 \quad$ References}

[1] Dahdouh-Guebas, F., Jayatissa, L.P., Di Nitto, D., Bosire, J.O., Lo Seen, D. \& Koedam, N., How effective were mangroves as a defence against the recent tsunami, Current Biology, 15(12), R443-R447, 2005. 
[2] Blasco, F., Saenger, P. \& Janodet, E., Mangrove as indicators of coastal change, Catena, 27(3-4), 167-178, 1996.

[3] Blasco, F., Aizpuru, M. \& Gers, C., Depletion of the mangroves of Continental Asia, Wetlands Ecology and Management, 9(3), 245-256, 2001.

[4] Diaz, B.M. \& Blackburn, G.A., Remote sensing of mangrove biophysical properties: evidence from a laboratory simulation of the possible effects of background variation on spectral vegetation indices, International Journal of Remote Sensing, 24(1), 53-73, 2003.

[5] Mougin, E., Proisy, C., Marty, G., Fromard, F., Puig, H., Betoulle, J.L. \& Rudant, J.P., Multifrequency and multipolarization radar backscattering from mangrove forests, IEEE Transactions on Geoscience and Remote Sensing, 37(1), 94-102, 1999.

[6] Aschbacher, J., Ofren, R., Delsol, J.P., Suselo, T.B., Vibulsresth, S. \& Charrupat, T., An integrated comparative approach to mangrove vegetation mapping using advanced remote sensing and GIS technologies: preliminary results, Hydrobiologia, 295(1-3), 285-294, 1995.

[7] Pasqualini, V., Iltis, J., Dessay, N., Lointier, M., Guelorget, O. \& Polidori, L., Mangrove mapping in North-western Madagascar using SPOT-XS and SIR-C radar data, Hydrobiologia, 413(0), 127-133, 1999.

[8] Simard, M., De Grandi, G., Saatchi, S. \& Mayaux, P., Mapping tropical coastal vegetation using JERS-1 and ERS-1 radar data with a decision tree classifier, International Journal of Remote Sensing, 23(7), 14611474, 2002.

[9] Held, A., Ticehurst, C., Lymburner, L. \& Williams, N., High-resolution mapping of tropical mangrove ecosystems using hyperspectral and radar remote sensing, International Journal of Remote Sensing, 24(13), 27392759, 2003.

[10] Cloude, S.R. \& Pottier, E., An entropy based classification scheme for land applications of polarimetric SAR, IEEE Transactions on Geoscience and Remote Sensing, 35(1), 67-78, 1997.

[11] Hellmann, M. Classification of fully polarimetric SAR data for cartographic applications, Dr.-Ing Dissertation, DLR Report FB 200019, Oberpfaffenhofen, Germany, 2000.

[12] Brunskill, G.J., Zagorskis, I., Pfitzner, J. \& Ellison, J. Sediment and trace element depositional history from the Ajkwa River estuarine mangroves of Irian Jaya (West Papua), Indonesia, Continental Shelf Research, 24(19), 2535-2551, 2004.

[13] Breiman, L., Friedman, J.H., Olshen, R.A. \& Stone, C.J., Classification and Regression Trees, Wadsworth, Monterey, 1984.

[14] Quinlan, J.R., C4.5: Programs for Machine Learning, Morgan Kaufmann, San Mateo, 1993. 
[15] Breiman, L., Random forests, Machine Learning, 45(1), 5-32, 2001.

[16] Van der Sanden, J.J. \& Hoekman, D.H., Potential of airborne radar to support the assessment of land cover in a tropical rain forest environment, Remote Sensing of Environment, 68(1), 26-40, 1999.

[17] Borghys, D., Yvinec, Y., Perneel, C., Pizurica, A. \& Philips, W., Supervised feature-based classification of multi-channel SAR images, Pattern Recognition Letters, 27(4), 252-258, 2006. 